\title{
LED Driver with TRIAC Dimming Control by Variable Switched Capacitance for Power Regulation
}

\author{
Eun-Soo Lee*, Yeung-Hoon Sohn`, Duy Tan Nguyen*, Jun-Pil Cheon", and Chun-Taek Rim* \\ *Department of Nuclear and Quantum Engineering, KAIST, Daejeon, Korea \\ 'Department of Electrical Engineering, KAIST, Daejeon, Korea
}

\begin{abstract}
A TRIAC dimming LED driver that can control the brightness of LED arrays for a wide range of source voltage variations is proposed in this paper. Unlike conventional PWM LED drivers, the proposed LED driver adopts a TRIAC switch, which inherently guarantees zero current switching and has been proven to be quite reliable over its long lifetime. Unlike previous TRIAC type LED drivers, the proposed LED driver is composed of an LC input filter and a variable switched capacitance, which is modulated by the TRIAC turn-on timing. Thus, the LED power regulation and dimming control, which are done by a volume resistor in the same way as the conventional TRIAC dimmers, can be simultaneously performed by the TRIAC control circuit. Because the proposed LED driver has high efficiency and a long lifetime with a high power factor (PF) and low total harmonic distortion (THD) characteristics, it is quite adequate for industrial lighting applications such as streets, factories, parking garages, and emergency stairs. A simple step-down capacitive power supply circuit composed of passive components only is also proposed, which is quite useful for providing DC power from an AC source without a bulky and heavy transformer. A prototype $60 \mathrm{~W}$ LED driver was implemented by the proposed design procedure and verified by simulation and experimental results, where the efficiency, PF, and THD are $92 \%, 0.94$, and $6.3 \%$, respectively. The LED power variation is well mitigated to below $\pm 2 \%$ for $190 \mathrm{~V}<V_{s}<250 \mathrm{~V}$ by using the proposed simple control circuit.
\end{abstract}

Key words: Controlled current mirror, DC power supply circuit, TRIAC dimming control, Variable switched capacitance

\section{INTRODUCTION}

Light emitting diodes (LEDs) are gradually replacing conventional fluorescent lamps and incandescent lights due to their higher efficacy and longer lifespans [1]-[8]. LED drivers provide regulated or controlled currents to LEDs for constant lighting or dimming, regardless of source voltage changes and temperature variations. Switch mode power supply (SMPS)-type LED drivers with pulse width modulation (PWM) switching, in the hundreds of $\mathrm{kHz}$ range, are widely used due to their compact filter size and fair total harmonic distortion (THD) characteristics. However, the SMPS-type LED drivers suffer from large switching losses and shorter lifespans than the LED itself due to the high junction

Manuscript received Oct. 29, 2014; accepted Dec. 16, 2014 Recommended for publication by Associate Editor Yan Xing.

${ }^{\dagger}$ Corresponding Author: ctrim@kaist.ac.kr

Tel: +82-42-350-3827, Fax: +82-42-350-3810, KAIST

Department of Electrical Engineering, KAIST, Korea

*Department of Nuclear and Quantum Eng., KAIST, Korea temperature of the main switches [9]-[20]. As an alternative solution, passive-type LED drivers are preferred due to their very high efficiency and extremely long lifespan [21]-[24]. However, the inherent drawbacks of the passive-type LED drivers include their lack of current regulation capability and a relatively large filter size, where this filter size problem can be mitigated by virtue of a reduced heat sink and a compact coil design. Therefore, the passive-type LED drivers may not be a good solution for the applications requiring a constant LED current regardless of source voltage variations.

LED dimming is widely used. It is generally achieved with by PWM switches [25]-[28] or TRIAC switches [29]-[32]. LED dimmers composed of a TRIAC and a DIAC with a variable resistor [29]-[32] have many merits such as a simple structure, high reliability, low cost, and high efficiency. However, these conventional TRIAC dimming LED drivers generally have poor THD characteristics because they are directly connected to the primary side of the source line. Though their power factor (PF) can be mitigated by using appropriate power converters [29]-[31], this type of dimmer 


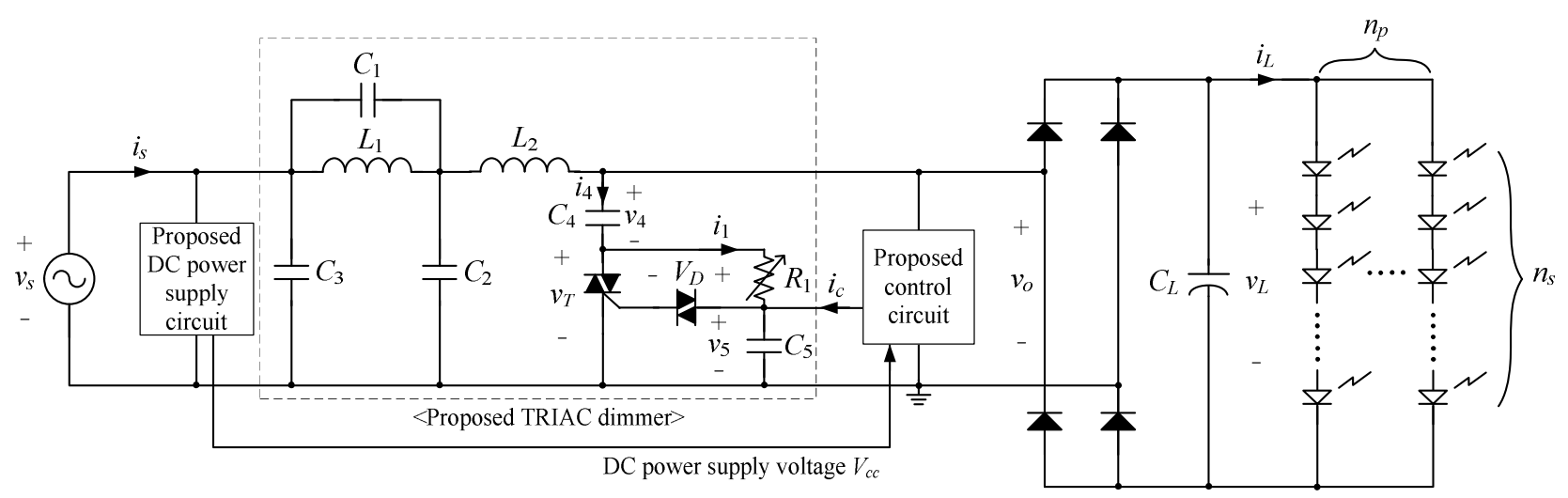

Fig. 1. Overall circuit diagram of the proposed TRIAC dimming LED driver.

is not adequate for high power LED applications due to THD and PF problems.

In this paper, a novel TRIAC dimming LED driver with a passive input filter is proposed, as shown in Fig. 1. This LED driver is based on the LC $^{3}$ passive-type LED driver configuration [24] to achieve a high efficiency and an extremely long lifespan. A dynamically variable switched capacitance is adopted to modulate the TRIAC turn-on timing so that the LED power can be controlled. Unlike the SMPS-type LED drivers, the proposed LED driver uses a TRIAC, which is a proven and quite robust device in home appliances, that inherently guarantees zero current switching (ZCS) with no additional circuits. The LED dimming is done by a volume resistor, which is similar to conventional manual TRIAC dimmers [29]-[32]. The validity of the proposed LED driver design is verified by simulation and experimental results. They show a successful regulation of LED power, and meet PF and THD standards over a wide range of source voltages.

\section{ANALYSIS OF THE PROPOSED TRIAC DIMMING LED DRIVER}

\section{A. Operating Principle of the Main Power Circuit in the Steady State}

The power circuit of the proposed LED driver, as shown in Fig. 1, is derived from the temperature-robust $\mathrm{LC}^{3}$ LED driver [24], which is a novel passive-type LED driver, that satisfies PF and THD regulations. In order to provide the power control function with the LED driver, a TRIAC switch with a DIAC is inserted in series with $C_{4}$ to vary the connecting time portion, which results in a variation of the equivalent capacitance, unlike with conventional variable capacitances [33]-[36]. An additional inductor $L_{2}$ is newly introduced in the proposed LED driver to prevent the TRIAC from having a large inrush current when it is turned on. Note that $n_{s}$ and $n_{p}$ are the numbers of LEDs in series and parallel, respectively. In this paper, all of the circuit components are assumed to be ideal unless otherwise specified.

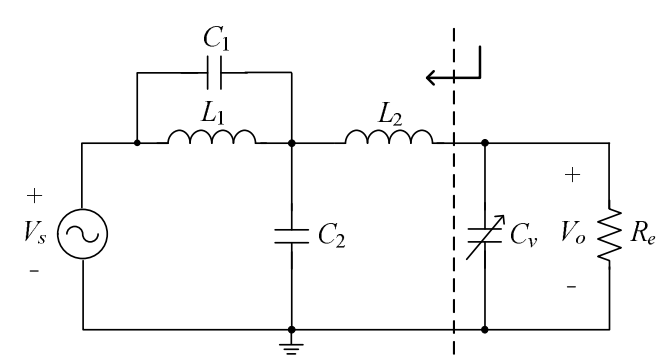

(a)

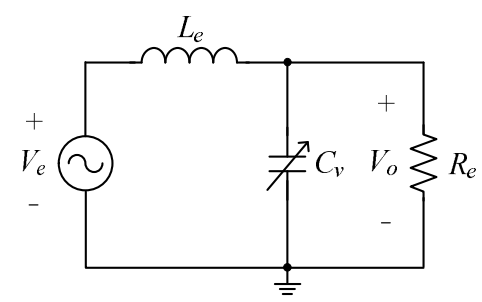

(b)

Fig. 2. A simplified static circuit of the proposed LED driver, neglecting harmonic components. (a) Simplified equivalent circuit of the proposed LED driver. (b) Further simplified circuit of (a).

As shown in Fig. 2(a), the simplified equivalent main power circuit of the proposed LED driver can be obtained by regarding the switched capacitor circuit of $C_{4}$ and the TRIAC as an equivalent variable capacitor $C_{v}$ and by simplifying the diode rectifier and DC load circuit as an equivalent resistor [23]-[24], [37]-[38] as follows:

$$
R_{e} \cong \alpha^{2} R_{L} \quad \because R_{L}=V_{L} / I_{L} \quad \alpha \cong 2 \sqrt{2} / \pi \cong 0.90,(1)
$$

where $\alpha$ is the $\mathrm{DC}$ to $\mathrm{AC}$ voltage conversion ratio when a bridge diode is converted to an equivalent auto-transformer [39]-[42].

In this section, the high-order switching harmonics are neglected from discussions and only the fundamental components of the voltages and currents are considered for simplification.

By applying Thevenin's theorem to the left part of the circuit in Fig. 2(a) in the steady state at the source angular frequency $\omega_{s}$, the proposed LED circuit can be converted to 


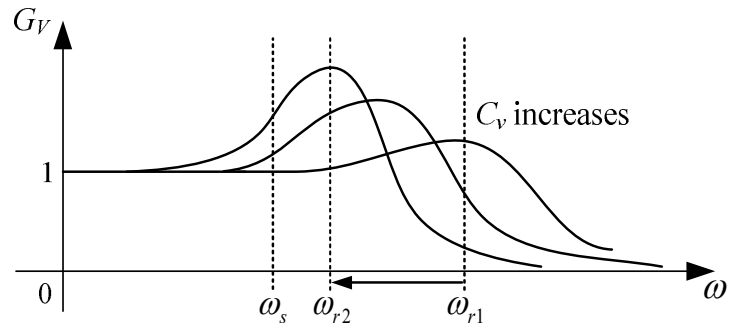

Fig. 3. The LED power regulation principle by variable switched capacitance.

that shown in Fig. 2(b), since $C_{1}$ and $C_{2}$ are small. Thus, $V_{e}$ and $L_{e}$ are found as follows:

$$
\begin{gathered}
V_{e}=\frac{V_{s}}{1-\omega_{s}^{2} L_{p} C_{2}}, \quad L_{e}=\frac{L_{p}}{1-\omega_{s}^{2} L_{p} C_{2}}+L_{2} \\
\because L_{p}=\frac{L_{1}}{1-\omega_{s}^{2} L_{1} C_{1}} .
\end{gathered}
$$

Therefore, the DC voltage gain $G_{V}$, which is the ratio of the output voltage $V_{o}$ and the source voltage $V_{s}$, is then determined as follows:

$$
\begin{aligned}
& G_{V}\left(C_{v}\right) \equiv\left|\frac{V_{o}}{V_{s}}\right|=\left|\frac{V_{e}}{V_{s}} \cdot \frac{V_{o}}{V_{e}}\right| \\
& =\frac{1}{\left(1-\omega_{s}^{2} L_{p} C_{2}\right)} \cdot \frac{R_{e}}{\sqrt{R_{e}^{2}\left(1-\omega_{s}^{2} L_{e} C_{v}\right)^{2}+\omega_{s}^{2} L_{e}^{2}}}
\end{aligned}
$$

As identified from (3), $G_{V}$ increases when $C_{v}$ increases as long as the source angular frequency $\omega_{s}$ is less than the resonant angular frequency $\omega_{r}$, which is exactly the case of the proposed design, i.e.:

$$
\omega_{s}<\omega_{r}, \quad \omega_{r}=\frac{1}{\sqrt{L_{e} C_{v}}} .
$$

The LED dissipating power, which is proportional to $V_{o}$, can be accordingly controlled by changing $C_{v}$, as shown in Fig. 3.

\section{B. Operating Principle of the TRIAC Dimmer in the Transient State}

The method for changing the capacitance $C_{v}$ by the proposed TRIAC dimmer, as shown in Fig. 1, is explained in this section.

When the TRIAC is completely turned off, as shown in Fig. 4(a), there is no capacitance, assuming the loading effect of $R_{1}-C_{5}$ is negligible. As a result, $C_{v}=0$. When the TRIAC is completely turned on, as shown in Fig. 4(b), the capacitance becomes $C_{v}=C_{4}$. If the TRIAC is appropriately turned on with a delay time of $T_{c}$ for every half cycle of the power source $T_{s}$, as shown in Fig. 5, the equivalent capacitance $C_{v}$ can be varied as follows:

$$
0 \leq C_{v}<C_{4} \text { for } T_{s} / 2 \geq T_{c}>0 .
$$

Unfortunately, it is not possible to find an analytical expression of $C_{v}$ for an arbitrary control time of $T_{c}$. This is due to difficulties in finding the dynamics of the fourth-order

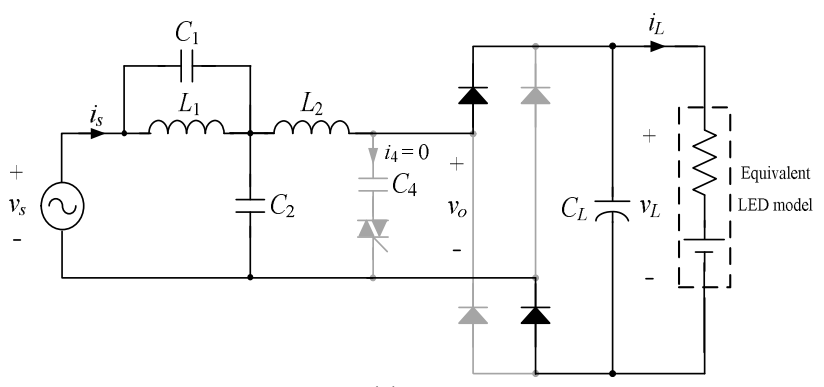

(a)

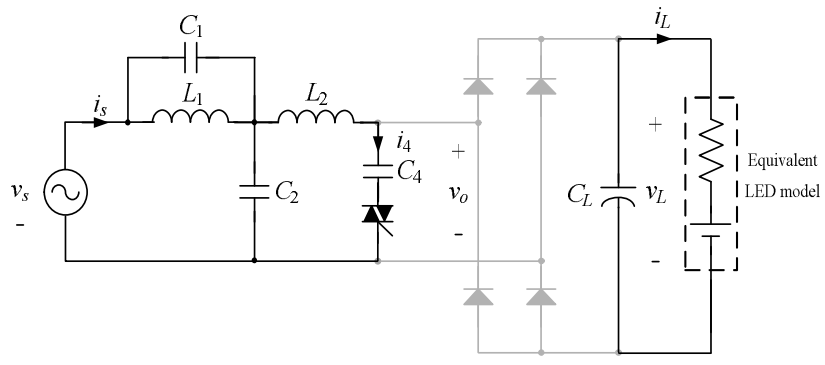

(b)

Fig. 4. Dynamic circuits of the proposed LED driver for a positive half cycle of the $v_{s}$, assuming the $v_{L}$ is constant due to a large load capacitor. (a) The TRIAC is turned off. (b) The TRIAC is turned on.

power circuit. Therefore, the dynamic characteristics and the DC gain of (3) are simulated for each $T_{c}$ in the subsequent section. Instead, the method for changing the value of $T_{c}$ is suggested in this section.

TRIAC-Off Mode [ $\left.\boldsymbol{t}_{1}, \boldsymbol{t}_{2}\right]$ : As shown in Fig. 4(a), the DIAC control input voltage $v_{5}$ is charged, when the TRIAC is turned off, as follows:

$$
\begin{gathered}
C_{5} \frac{d v_{5}}{d t}=i_{1}-i_{c}=\frac{v_{T}-v_{5}}{R_{1}}-i_{c} \cong \frac{v_{T}}{R_{1}}-i_{c} \cong \frac{2 V_{L}}{R_{1}}-i_{c} \\
\because\left|v_{5}\right| \leq V_{D}<<V_{L}<2 V_{L} \cong\left|v_{T}\right|
\end{gathered}
$$

In (6), it is assumed that the LED voltage and capacitor voltage are unchanged, i.e. $v_{o}=v_{L}=V_{L}$ and $v_{4}=-V_{L}$, respectively. As a result, the TRIAC voltage is determined as $v_{T}=v_{o}-v_{4} \approx V_{L}-\left(-V_{L}\right)=2 V_{L}$. Moreover, $v_{4}$ is nearly constant because $R_{1}$ is set to be as high as several M $\Omega$. The DIAC triggering voltage $V_{D}$ is set to be $32 \mathrm{~V}$ in this paper, which is much less than $V_{L} \approx 210 \mathrm{~V}$. The capacitor voltage $v_{4}$ has been determined by the previous switching stage, which will be explained in the next few paragraphs.

TRIAC-On Mode $\left[\boldsymbol{t}_{2}, \boldsymbol{t}_{3}\right]$ : As $v_{5}$ reaches $V_{D}$, the DIAC and TRIAC are turned on, and $C_{5}$ is immediately discharged so that $v_{5}$ becomes zero, as shown in Fig. 4(b). At the same time, the capacitor voltage of $C_{4}$ is resonated with $L_{2}$ and other filter elements, and its voltage $v_{4}$ is increased from $-V_{L}$ at $\mathrm{t}=t_{2}$ to $V_{L}$ at $\mathrm{t}=t_{3}$, as shown in Fig. 5. Note that $v_{4}$ is kept constant until the TRIAC is turned on again at the next negative polarity of source voltage. As soon as $v_{4}$ reaches $V_{L}$, the TRIAC is turned off because the time derivative of the 


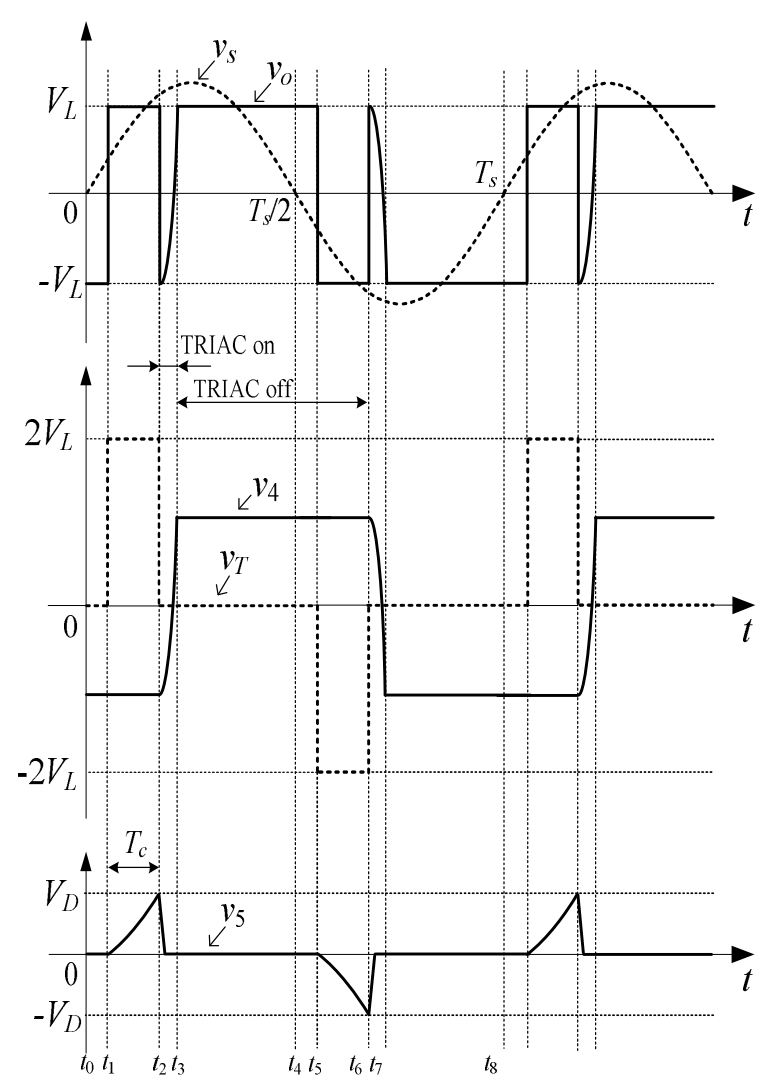

Fig. 5. Waveforms of the TRIAC dimmer.

capacitor voltage is eventually zero, i.e., $i_{4}=C_{4} \frac{d v_{4}}{d t}=C_{4} \frac{d V_{L}}{d t}=0$. Therefore, the TRIAC is kept turned off during $\left[t_{3}, t_{6}\right]$, where its voltage becomes negative at $\mathrm{t}=t_{5}$ due to a reversed turning on of the full bridge diode.

The control time $T_{c}$, as shown in Fig. 5, can be derived from (6), assuming $i_{c}=I_{c}$ for a half cycle, as follows:

$$
C_{5} \frac{V_{D}}{T_{c}} \cong \frac{2 V_{L}}{R_{1}}-I_{c} \quad \rightarrow \quad T_{c}=\frac{V_{D} R_{1} C_{5}}{2 V_{L}-I_{c} R_{1}} .
$$

From (7), $T_{c}$ can be normalized by $R_{1} C_{5}$, as follows:

$$
\beta \equiv \frac{T_{c}}{R_{1} C_{5}}=\frac{V_{D}}{2 V_{L}-I_{c} R_{1}} .
$$

As shown in Fig. 6, $\beta$, which is proportional to $T_{c}$, can be controlled by either the manual dimming volume resistor $R_{1}$ or the control current $I_{c}$ so that the LED power can eventually be varied.

\section{Operating Principle of the Control Circuit}

In order to feed an appropriate $I_{c}$ of (8) against variations in the LED voltage $V_{L}$, a control circuit is introduced, as shown in Fig. 7, where the input and output of the proposed circuit are connected to $v_{o}$ and $v_{5}$ of Fig. 1, respectively.

The proposed control circuit is composed of a negative peak detector for detecting the envelope of the load voltage, a low pass filter for eliminating harmonic voltage ripples higher than the source frequency of $50 \mathrm{~Hz}$ or $60 \mathrm{~Hz}$, an

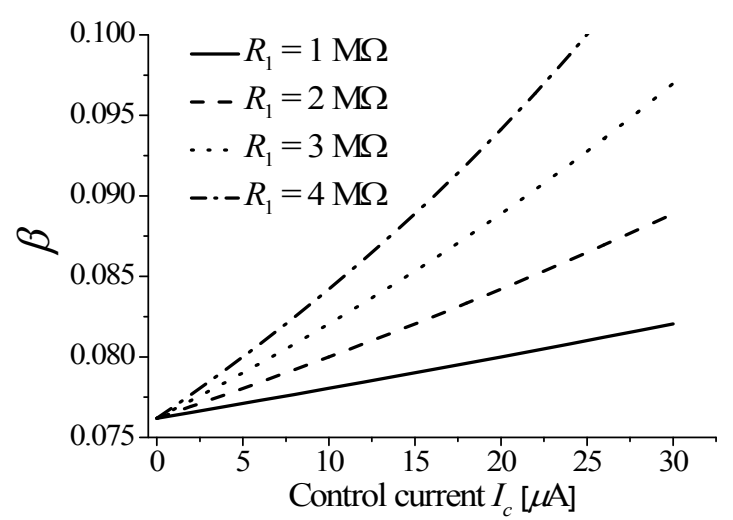

Fig. 6. An example of theoretical normalized control time $T_{c} /\left(R_{1} C_{5}\right)$ w.r.t. $I_{c}$ for various $R_{1}$ when $V_{D}=32 \mathrm{~V}$ and $V_{L}=210 \mathrm{~V}$.

integrator to accumulate the control error signals, and a current mirror for converting the control voltage $v_{c}$ to the control current $i_{c}$.

As shown in Fig. 5, $v_{o}$ and $v_{5}$ alternatively change every half cycle. Therefore, it is not feasible to derive a transfer function from the proposed control circuit as it is. Instead, the envelope behavior of $v_{o}$ and $v_{5}$ is considered in this section.

The resistors $R_{6}$ and $R_{7}$ constitute a mathematical comparator as follows:

$$
\begin{gathered}
v_{f 1}=\frac{R_{6}}{R_{6}+R_{7}} V_{c c}+\frac{R_{7}}{R_{6}+R_{7}} v_{o} \equiv V_{r e f}+K v_{o} \\
\because V_{r e f}=\frac{R_{6}}{R_{6}+R_{7}} V_{c c}, K=\frac{R_{7}}{R_{6}+R_{7}} \\
v_{f 2} \cong \frac{R_{6}}{R_{6}+R_{7}} V_{c c}-\frac{R_{7}}{R_{6}+R_{7}} v_{o}^{*}=V_{r e f}-K v_{o}^{*} \\
\Rightarrow \quad V_{f 2}(s) \cong V_{r e f}(s)-K V_{o}^{*}(s),
\end{gathered}
$$

where the constant DC supply voltage $V_{c c}$ is used to generate the reference voltage $V_{\text {ref }}$. In (9b), a non-linear negative peak detector is approximated to a rectifier for the envelope of each peak voltage $v_{o}^{*}$.

The low pass filter and integrator have the following transfer functions, respectively:

$$
\begin{gathered}
G_{1}(s) \equiv \frac{V_{f 3}(s)}{V_{f 2}(s)}=\frac{R_{3} / / R_{5}}{R_{3} / / R_{5}+R_{4}} \cdot \frac{1}{1+s C_{7}\left(R_{3} / / R_{4} / / R_{5}\right)} \\
G_{2}(s) \equiv \frac{V_{c}(s)}{V_{f 3}(s)}=-\frac{1}{s R_{3} C_{6}},
\end{gathered}
$$

where a positive offset current is provided through $R_{5}$ in the low pass filter because the negative peak detector is a current sink.

The current mirror provides the control current $\underline{I}_{\underline{c}}$ of (8), regardless of the polarity, in proportion to $\underline{v}_{c}$ as follows:

$$
\begin{gathered}
i_{c}=i_{m} \text { for } v_{5}>V_{\gamma}+V_{\sigma}\left(\because D_{1}=D_{2}=\mathrm{OFF}, D_{3}=D_{4}=\mathrm{ON}\right)(11 \mathrm{a}) \\
i_{c}=-i_{m} \text { for } v_{5}<-V_{\gamma}\left(\because D_{1}=D_{2}=\mathrm{ON}, D_{3}=D_{4}=\mathrm{OFF}\right)(11 \mathrm{~b}) \\
i_{c}=0 \text { for }-V_{\gamma} \leq v_{5} \leq V_{\gamma}+V_{\sigma}\left(\because D_{1}=D_{2}=D_{3}=\mathrm{OFF}, D_{4}=\mathrm{ON}\right)(11 \mathrm{c})
\end{gathered}
$$




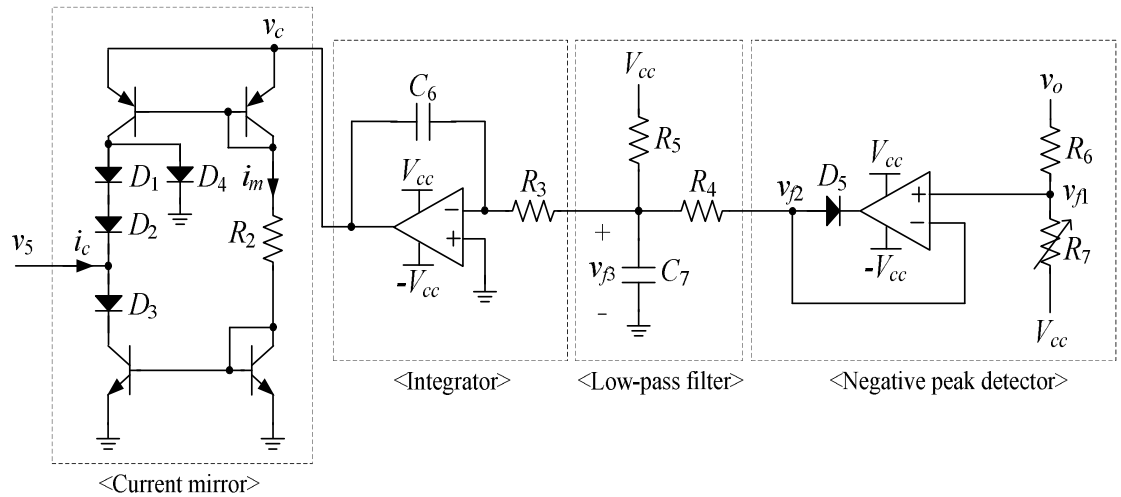

Fig. 7. Proposed control circuit for LED power regulation.

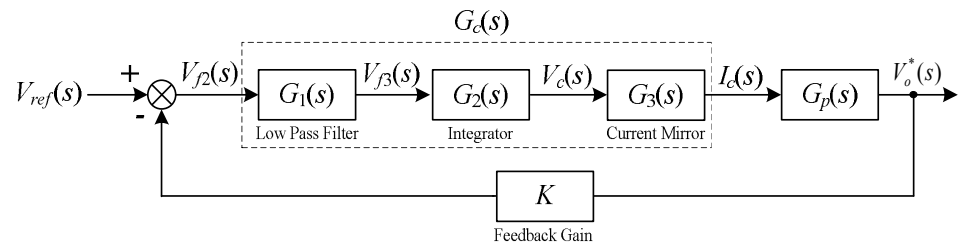

Fig. 8. Overall block diagram of the proposed TRIAC dimming LED driver including the control circuit.

$$
\begin{gathered}
\because i_{m}=\frac{v_{c}-2 V_{\gamma}}{R_{2}} \\
\Rightarrow I_{c}(s)=\Delta I_{m}(s)=\frac{1}{R_{2}} V_{c}(s) \\
\therefore \quad G_{3}(s) \equiv \frac{I_{c}(s)}{V_{c}(s)}=\frac{1}{R_{2}},
\end{gathered}
$$

where $V_{\gamma}$ and $V_{\sigma}$ are the cut-in voltage $(\cong 0.6 \mathrm{~V})$ and saturation voltage $(\cong 0.2 \mathrm{~V})$ of a bipolar junction transistor, respectively.

As can be seen from (11a) and (11b), the current mirror operates nearly symmetrically w.r.t. $v_{5}$, which is essential for symmetrical control of each half cycle. In (11e), the DC offset term of (11d) is omitted from the transfer function of $I_{c}(s)$ of (8) because this offset is relatively small and can be cancelled by the integrator. Therefore, only the change of the mirror current $i_{m}$ is considered.

As shown in Fig. 8, the overall closed-loop transfer function of the proposed TRIAC dimming LED driver can be found from (9)-(11) as follows:

$$
\begin{gathered}
G_{s}(s) \equiv \frac{V_{o}^{*}(s)}{V_{r e f}(s)}=\frac{G_{c}(s) G_{p}(s)}{1+K G_{c}(s) G_{p}(s)} \\
\because G_{p}(s) \equiv \frac{V_{o}^{*}(s)}{I_{c}(s)}, \\
G_{c}(s) \equiv G_{1}(s) \cdot G_{2}(s) \cdot G_{3}(s) \\
=\frac{R_{3} / / R_{5}}{R_{3} / / R_{5}+R_{4}} \cdot \frac{1}{1+s C_{7}\left(R_{3} / / R_{4} / / R_{5}\right)} \cdot \frac{-1}{s R_{3} C_{6}} \cdot \frac{1}{R_{2}}
\end{gathered}
$$

In (12), the LED system transfer function $G_{p}(s)$ has a negative gain as identified from (3) and (8). In other words, $T_{c}$ increases as $I_{c}$ increases, which results in decreases of $C_{v}$ and $V_{o}$. The LED voltage $V_{L}$, which is the final control goal, is indirectly controlled by $V_{o}\left(\cong \alpha V_{L}\right.$ ) from (12).

In many cases, the power regulation of LED drivers is not necessarily very fast. Thus, the proposed control circuit is designed to be slow enough so that it can be quite robust to switching noise and disturbances. Then, assuming that the low pass filter and LED system are fast enough when compared to the integrator, the loop gain of (12a) becomes as follows:

$$
\begin{aligned}
& L G(s) \equiv 1+K G_{c}(s) G_{p}(s) \\
& =1+K G_{1}(s) \cdot G_{2}(s) \cdot G_{3}(s) G_{p}(s) \\
& \cong 1+K G_{2}(s) \cdot G_{3}(s) G_{p 0}=1+\frac{K G_{p 0}}{s R_{3} C_{6} R_{2}}=0 \\
& \quad \because \quad G_{p 0} \equiv-G_{p}(0)>0, G_{1}(s) \cong 1 \\
& \Rightarrow s_{o}=-\frac{K G_{p 0}}{R_{2} R_{3} C_{6}} \text { or } \Rightarrow \tau=\frac{R_{2} R_{3} C_{6}}{K G_{p 0}} .
\end{aligned}
$$

As identified from (13c), the proposed LED driver is always stable and its first-order time constant can be adjusted by the control gain.

\section{DESIGN OF THE PROPOSED TRIAC DIMMING LED DRIVER}

\section{A. Main Circuit}

As shown in Fig. 1, the proposed LED driver includes a passive-type LC $^{3}$ LED driver [24]; hence, the main power circuit parameters for $60 \mathrm{~W}$ of power were chosen in a similar way to those of the references [24], as listed in the Table I.

Concerning the TRIAC dimmer in Fig. 1, a small value of 
TABLE I

Circuit Parameters of the Proposed Main Power Circuit

\begin{tabular}{c|c||c|c}
\hline \hline Parameters & Values & Parameters & Values \\
\hline$L_{1}$ & $0.6 \mathrm{H}$ & $C_{5}$ & $10 n \mathrm{~F}$ \\
\hline$L_{2}$ & $0.6 \mathrm{H}$ & $C_{L}$ & $100 \mu \mathrm{F}$ \\
\hline$C_{1}$ & $0.47 \mu \mathrm{F}$ & $R_{1}$ & $1.0 \mathrm{M} \Omega$ \\
\hline$C_{2}$ & $0.68 \mu \mathrm{F}$ & $V_{D}$ & $32 \mathrm{~V}$ \\
\hline$C_{3}$ & $1.68 \mu \mathrm{F}$ & $n_{s}$ & 70 \\
\hline$C_{4}$ & $1.0 \mu \mathrm{F}$ & $n_{p}$ & 4 \\
\hline \hline
\end{tabular}

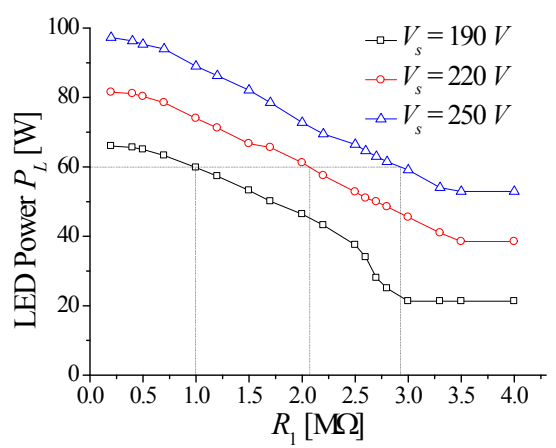

Fig. 9. Simulation results of the LED power w.r.t. $R_{1}$ for various $V_{s .}$

$C_{5}$ and a large value of $R_{1}$ are highly recommended for reducing the capacitor size and power loss in $R_{1}$. Thus, $C_{5}$ and $R_{1}$ are chosen as $10 n \mathrm{~F}$ and $1.0 \sim 3.0 \mathrm{M} \Omega$, respectively. The worst case power dissipation in $R_{1}$ is roughly $\left(2 V_{L}\right)^{2} / R_{1} \cong(2 \cdot 210)^{2} / 1 \mathrm{M} \cong 176.4 \mathrm{~mW}$, which is well below $1 / 4 \mathrm{~W}$. The value of $C_{4}$ is selected as $1.0 \mu \mathrm{F}$, considering the range of variable switched capacitance. The breakover voltage $V_{D}$ of the DIAC is selected as $32 \mathrm{~V}$, considering the commercial availability of the DIAC.

To confirm LED dimming by a volume resistor $R_{1}$, a PSIM simulation was performed, as shown in Fig. 9. As $R_{1}$ increases, $T_{c}$ increases according to (7), and $C_{v}$ decreases, which results in a decrease of the LED power, as shown in Fig. 9. In this way, LED dimming by a volume resistor can be achievable for a wide range of source voltages, like a conventional dimming lamp. For a constant LED power $P_{L}=$ $60 \mathrm{~W}, R_{1}$ should be appropriately varied between 1.0 and 3.0 $\mathrm{M} \Omega$ for a source voltage of $190 \mathrm{~V}<V_{s}<250 \mathrm{~V}$, which is a \pm $30 \mathrm{~V}$ variation of the rated source voltage of $220 \mathrm{~V}$. For a constant source voltage of $V_{s}=220 \mathrm{~V}$, the LED power can be varied from $40 \mathrm{~W}$ to $80 \mathrm{~W}$.

\section{B. Control Circuit}

To sense the envelope of each peak voltage $v_{o}^{*}$, as shown in Fig. 7, a large value for $R_{6}$ is recommended for reducing the power loss in the resistor; hence, $R_{6}$ is set to $4.7 \mathrm{M} \Omega$ so that the worst case power dissipation in $R_{6}$ can be roughly 10 $m \mathrm{~W}$. In other words, $V_{L}^{2} / R_{6} \cong 210^{2} / 4.7 \mathrm{M} \cong 9.4 \mathrm{~mW}$, which is much lower than $1 / 4 \mathrm{~W}$. In the steady state, the $v_{f 2}$ of (9b) should be zero, assuming that $R_{5}$ is large enough, so that the input voltage of the integrator can be zero. Thus, for a given $V_{L}$ that is determined from [24], $R_{7}$ is calculated as 336 $k \Omega$, as follows:

$$
\begin{aligned}
& \frac{R_{6}}{R_{6}+R_{7}} V_{c c} \cong \frac{R_{7}}{R_{6}+R_{7}} V_{o}^{*}\left(\because V_{f 2}=0\right) \\
& \rightarrow R_{7} \cong \frac{V_{c c}}{V_{o}^{*}} R_{6} \cong \frac{V_{c c}}{V_{L}} R_{6}=\frac{15}{210} 4.7 \mathrm{M}=336 \mathrm{k} \Omega
\end{aligned}
$$

Harmonic voltage components higher than the third harmonic of the source frequency $f_{s}$ are assumed to be eliminated by the low pass filter. In other words, the time constant of the low pass filter, $R_{4} C_{7}$ is approximately $1 \mathrm{~ms}$, which results in the selection of $R_{4}=10 \mathrm{k} \Omega$ and $C_{7}=0.1 \mu \mathrm{F}$. For $V_{c c}=15 \mathrm{~V}, R_{5}$ is selected as $2.0 \mathrm{M} \Omega$ to provide a positive offset current of about $7.5 \mu \mathrm{A}$, which is a requisite for maintaining the non-negative polarity of $v_{f 3}$.

In the current mirror of Fig. 7, the maximum value for $I_{1}$ of Fig. 1 is calculated as $0.42 \mathrm{~mA}$ from (6) when $R_{1}=1.0 \mathrm{M} \Omega$ and $V_{L}=V_{o}^{*}=210 \mathrm{~V}$. As can be seen from Fig. 9, the maximum value of $R_{1}$ for $190 \mathrm{~V}<V_{s}<250 \mathrm{~V}$ is $2.9 \mathrm{M} \Omega$, which corresponds to almost a third of $I_{1}$, i.e. $0.14 \mathrm{~mA}$; hence, the maximum control current $I_{c, \max }=I_{m, \max }$ becomes $0.28 \mathrm{~mA}$ to give this current difference. Then, $R_{2}$ is approximately calculated from (11d) as $43.2 \mathrm{k} \Omega$, where $V_{\gamma}=0.7 \mathrm{~V}$ and the maximum value of $v_{c}$ is $13.5 \mathrm{~V}$.

Finally, the integrator is designed, where the time constant of this integrator $R_{3} C_{6}$ can be determined from (13c). From (9a), $K$ is calculated to be 0.0667 , and the system gain $G_{p 0}$ is experimentally determined to be $2.3 \times 10^{5}$. Therefore, $R_{3} C_{6}$ becomes $14 \mathrm{~ms}$, and the values of $R_{3}$ and $C_{6}$ are selected as $300 k \Omega$ and $47 n \mathrm{~F}$, respectively, considering a sufficiently slow response time of $400 \mathrm{~ms}$.

\section{DC Power Supply}

To provide the control circuit with supply voltages of $V_{c c}$ and $-V_{c c}$, a new DC power supply circuit is introduced, as shown in Fig. 10. Because the source voltage is very high when compared to the DC supply voltage, a new capacitive voltage divider of $C_{8}$ and $C_{9}$ is used. This simple circuit constitutes a step-down capacitive transformer, which may be replaced with a conventional inductive transformer and provides a galvanic isolation from the source voltage. In this paper, it is assumed that $V_{c c}$ and $-V_{c c}$ are symmetrical. In other words, $C_{10}=C_{11}$, and the zenor diode voltage $V_{z}$ is the same.

By applying Thevenin's theorem to Fig. 10(a), an equivalent circuit is obtained, as shown in Fig. 10(b), where the parameters are determined as follows:

$$
v_{t h}=\frac{C_{8}}{C_{8}+C_{9}} v_{s} \text { and } C_{t h}=C_{8}+C_{9} .
$$

The analysis of Fig. 10(b) is straightforward if the input current of a half cycle is found for a given $V_{z}$. This analysis is already available [43]-[44], assuming that $C_{10}>C_{t h}$ and that 


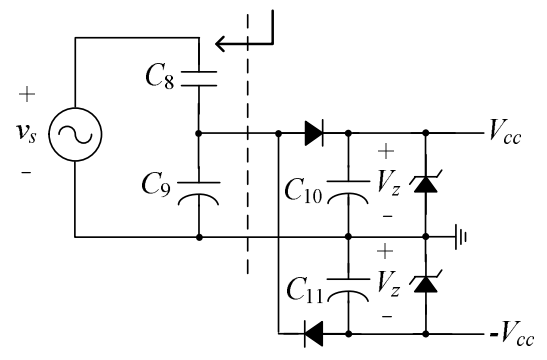

(a)

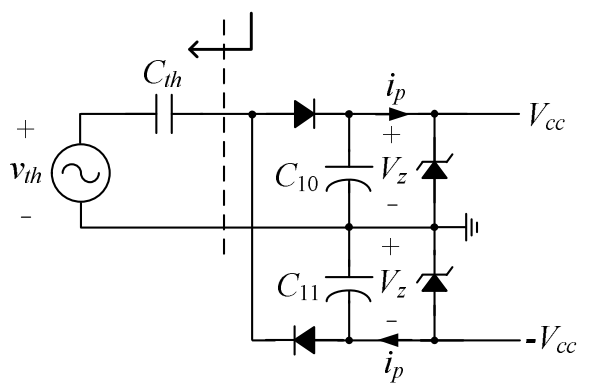

(b)

Fig. 10. Proposed capacitive transformer type DC power supply. (a) Original circuit. (b) Thevenin's equivalent circuit.

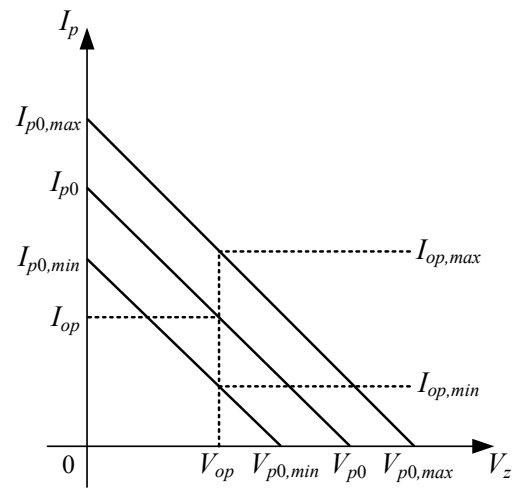

Fig. 11. The $V_{z}-I_{p}$ curve of the proposed DC power supply circuit.

the full bridge rectifier circuit is replaced with the proposed positive and negative rectifiers. Then, the average current of the positive DC side power supply $I_{p}$ becomes as follows, neglecting the diode forward voltage drop [44]-[45]:

$$
\begin{gathered}
I_{p}=I_{p 0}\left(1-\frac{V_{z}}{V_{p 0}}\right) \\
\because I_{p 0}=\frac{V_{t h} / 2}{1 /\left(\omega_{s} C_{t h}\right)}=\frac{\omega_{s} C_{t h} V_{t h}}{2} \text { and } V_{p 0}=\sqrt{2} V_{t h}
\end{gathered}
$$

In (16), $I_{p 0}$ corresponds to the shorted load circuit where $V_{z}$ $=0$, and $V_{p 0}$ corresponds to an open load circuit where $I_{p}=0$.

As can be seen from Fig. 11, the average DC current $I_{p}$ varies as the source voltage changes for $V_{s}=190 \mathrm{~V}, 220 \mathrm{~V}$, and $250 \mathrm{~V}$, respectively. When $V_{s}=190 \mathrm{~V}$, for a given $V_{z}=$ $V_{c c}=15 \mathrm{~V}, I_{p}$ becomes its minimum value $I_{o p, \text { min }}$, which should be larger than the required load current of the positive power supply $I_{p, r e q}$. Meanwhile, when $V_{s}=250 \mathrm{~V}, I_{p}$ becomes
TABLE II

Circuit Parameters of the Proposed Control Circuit and DC POWER SUPPLY

\begin{tabular}{c|c||c|c}
\hline \hline Parameters & Values & Parameters & Values \\
\hline$R_{2}$ & $43.2 \mathrm{k} \Omega$ & $C_{7}$ & $0.1 \mu \mathrm{F}$ \\
\hline$R_{3}$ & $300 \mathrm{k} \Omega$ & $C_{8}$ & $0.1 \mu \mathrm{F}$ \\
\hline$R_{4}$ & $10 \mathrm{k} \Omega$ & $C_{9}$ & $1.0 \mu \mathrm{F}$ \\
\hline$R_{5}$ & $2.0 \mathrm{M} \Omega$ & $C_{10}$ & $10 \mu \mathrm{F}$ \\
\hline$R_{6}$ & $4.7 \mathrm{M} \Omega$ & $C_{11}$ & $10 \mu \mathrm{F}$ \\
\hline$R_{7}$ & $336 \mathrm{k} \Omega$ & $V_{z}$ & $15 \mathrm{~V}$ \\
\hline$C_{6}$ & $47 n \mathrm{~F}$ & & \\
\hline \hline
\end{tabular}

its maximum $I_{o p, \max }$, which means that the zenor diode current, which is the difference between $I_{p}$ and the required load current, becomes large. Because the zenor diode current should be neither zero nor too large, the operating voltage $V_{o p}$ and the operating current $I_{o p}$ are chosen to be half of $V_{p 0}$ and $I_{p 0}$ at the normal source voltage of $V_{s, n o r m}=220 \mathrm{~V}$, as follows:

$$
\begin{gathered}
V_{o p}=V_{c c}=\frac{V_{p 0}}{2}=\frac{\sqrt{2} V_{\text {th, norm }}}{2}=\frac{V_{\text {th, norm }}}{\sqrt{2}} \\
\because V_{\text {th }, \text { norm }}=\frac{C_{8}}{C_{8}+C_{9}} V_{s, \text { norm }} .
\end{gathered}
$$

On the other hand, the minimum DC current $I_{o p, \min }$ at the minimum source voltage of $V_{s, \min }=190 \mathrm{~V}$ should always be larger than the required load current $I_{p, r e q}$, as follows:

$$
\begin{gathered}
I_{o p, \text { min }} \equiv I_{p 0, \text { min }}\left(1-\frac{V_{o p}}{V_{p 0, \text { min }}}\right) \geq I_{p, r e q} \\
\because I_{p 0, \text { min }}=\frac{\omega_{s} C_{t h} V_{t h, \text { min }}}{2}, \quad V_{p 0, \text { min }}=\sqrt{2} V_{t h, \text { min }}=\frac{\sqrt{2} C_{8}}{C_{8}+C_{9}} V_{s, \text { min }} .
\end{gathered}
$$

In this paper, the required DC power is identified as $V_{o p}=$ $V_{c c}=15 \mathrm{~V}$ and $I_{p, \text { req }}=1.5 \mathrm{~mA}$ at $f_{s}=60 \mathrm{~Hz}$; hence, $V_{p 0}$ is selected as $30 \mathrm{~V}$. From (17)-(18), $C_{8}$ and $C_{9}$ are calculated as $0.099 \mu \mathrm{F}$ and $0.932 \mu \mathrm{F}$, respectively. Hence, $C_{8}$ and $C_{9}$ are selected as $0.1 \mu \mathrm{F}$ and $1.0 \mu \mathrm{F}$, considering commercial product availability. To filter out the ripple in the supply voltage $V_{c c}$, both $C_{10}$ and $C_{11}$ are selected as $10 \mu \mathrm{F}$, which is about ten times greater than $C_{t h}$.

The design parameters of the proposed control circuit and DC power circuit are summarized in Table II.

\section{EXPERIMENTAL VERIFICATIONS}

As shown in Fig. 12, a prototype of the proposed LED driver was fabricated in accordance with the proposed design procedure, as listed in Tables I and II. The core material in the two inductors $L_{1}$ and $L_{2}$ of Fig. 12 was silicon steel plate core, and the internal resistance of the fabricated inductors was measured as $7 \Omega$. Because the proposed LED driver can be used for high LED power applications whose power level 


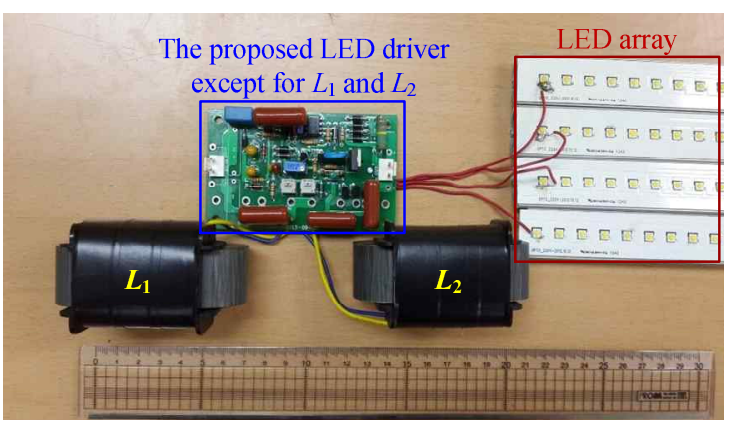

Fig. 12. A prototype of the proposed LED driver with two inductors $L_{1}$ and $L_{2}$ and an LED array.

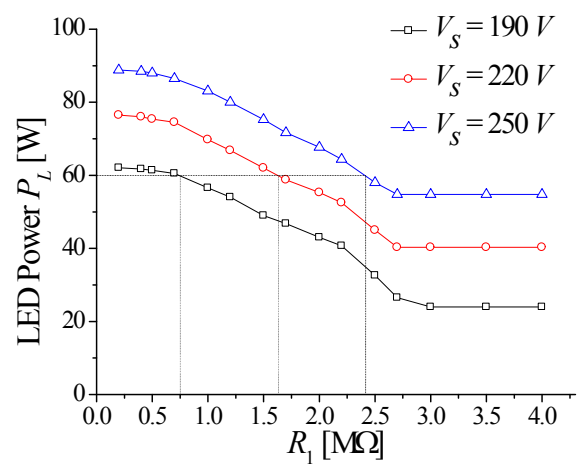

Fig. 13. Experimental results of LED power with respect to $R_{1}$ for various $V_{s}$.

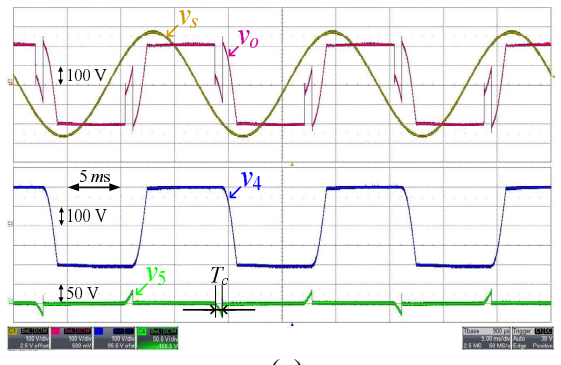

(a)

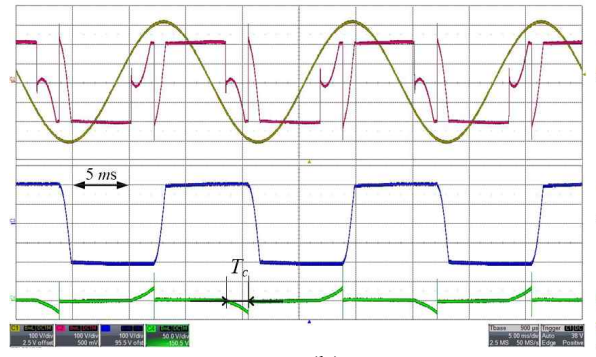

(b)

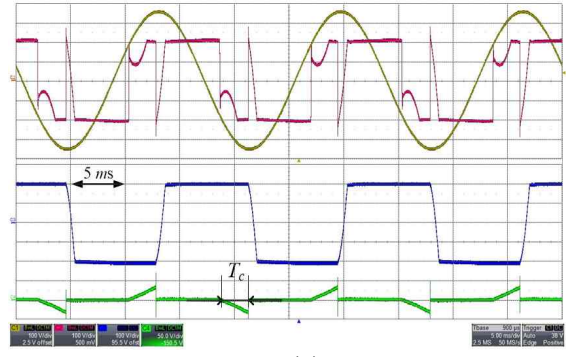

(c)

Fig. 14. The experimental waveforms of $v_{s}, v_{o}, v_{4}$, and $v_{5}$ for $V_{s}=190 \mathrm{~V}, 220 \mathrm{~V}$, and $250 \mathrm{~V}$ at $f_{s}=60 \mathrm{~Hz}$. (a) $V_{s}=190 \mathrm{~V}: R_{1}=0.75 \mathrm{M} \Omega$. (b) $V_{s}=220 \mathrm{~V}: R_{1}=1.63 \mathrm{M} \Omega$. (c) $V_{s}=250 \mathrm{~V}: R_{1}=2.4 \mathrm{M} \Omega$.

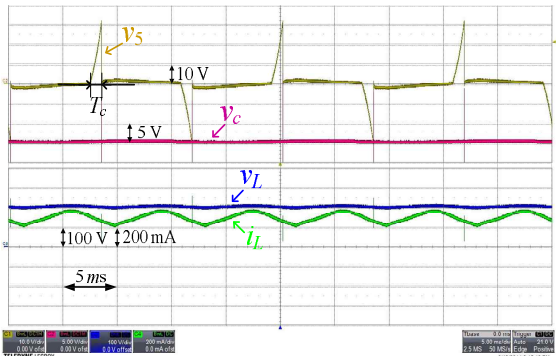

(a)

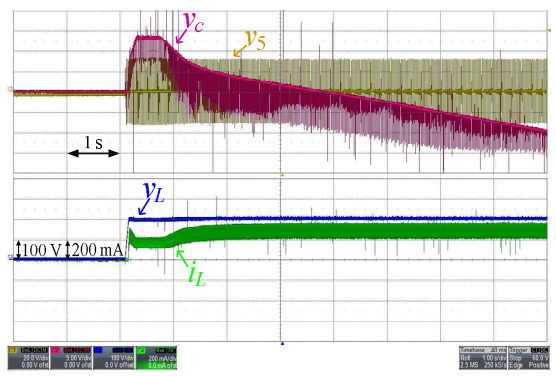

(d)

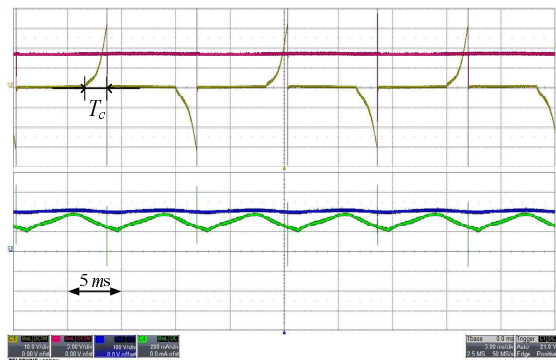

(b)

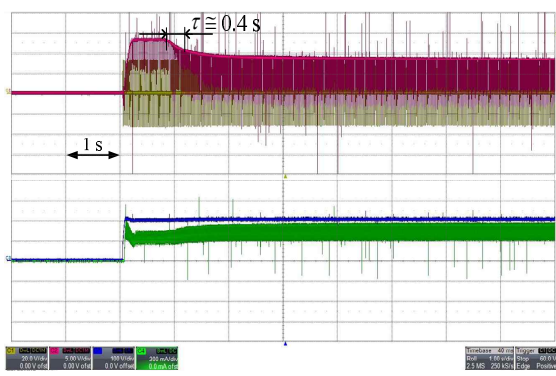

(e)

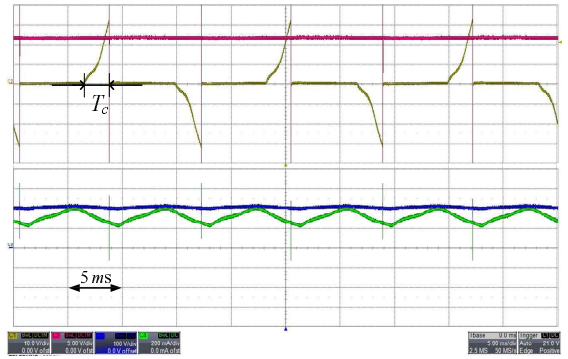

(c)

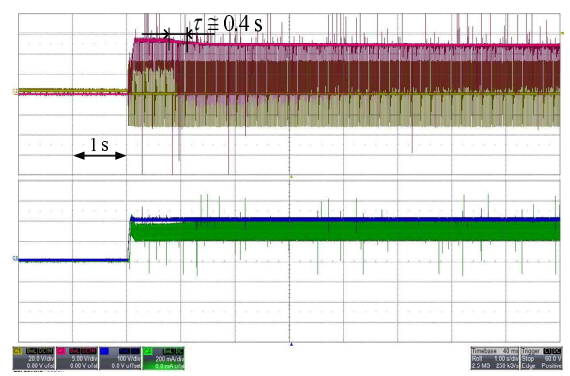

(f)

Fig. 15. The experimental waveforms of $v_{5}, v_{c}, i_{L}$, and $v_{L}$ for $V_{s}=190 \mathrm{~V}, 220 \mathrm{~V}$, and $250 \mathrm{~V}$ at $f_{s}=60 \mathrm{~Hz}$. (a) $V_{s}=190 \mathrm{~V}$ : time scale $=5 \mathrm{~ms}$. (b) $V_{s}=220 \mathrm{~V}$ : time scale $=5 \mathrm{~ms}$. (c) $V_{s}=250 \mathrm{~V}$ : time scale $=5 \mathrm{~ms}$. (d) $V_{s}=190 \mathrm{~V}$ : time scale $=1 \mathrm{~s}$. (e) $V_{s}=220 \mathrm{~V}$ : time scale $=1 \mathrm{~s}$. (f) $V_{s}=250 \mathrm{~V}$ : time scale $=1 \mathrm{~s}$.

is as high as $60 \sim 100 \mathrm{~W}$, two slightly large inductors are of no practical concern due to the large accommodation space of industrial lighting applications. These applications generally require high efficiency and a long lifespan for an LED driver.

\section{A. LED Dimming}

As shown in Fig. 13, the LED dimming of the proposed LED driver without a control circuit is experimentally verified. It is well matched with the simulation results of Fig. 9. Slight discrepancies between the experimental and simulation results come mainly from the internal resistances of $L_{1}$ and $L_{2}$. The value of $P_{L}$ can be set appropriately by 
TABLE III

Measured Results for Source Voltage Variation $\left(190 \mathrm{~V}<V_{S}<250 \mathrm{~V}\right)$

\begin{tabular}{c|c|c|c}
\hline \hline \multirow{2}{*}{$\begin{array}{c}\text { Measured } \\
\text { Parameters }\end{array}$} & \multicolumn{3}{|c}{ Source voltage $\left(V_{s}\right)$} \\
\cline { 2 - 4 } & $190 \mathrm{~V}_{\mathrm{rms}}$ & $220 \mathrm{~V}_{\mathrm{rms}}$ & $250 \mathrm{~V}_{\mathrm{rms}}$ \\
\hline$P_{s}$ & $62.6 \mathrm{~W}$ & $63.7 \mathrm{~W}$ & $66.5 \mathrm{~W}$ \\
\hline$P_{L}$ & $58.4 \mathrm{~W}$ & $58.8 \mathrm{~W}$ & $60.6 \mathrm{~W}$ \\
\hline $\mathrm{PF}$ & 0.979 & 0.940 & 0.912 \\
\hline $\mathrm{THD}$ & $7.0 \%$ & $6.3 \%$ & $10.8 \%$ \\
\hline Efficiency & $93.3 \%$ & $92.3 \%$ & $91.1 \%$ \\
\hline \hline
\end{tabular}

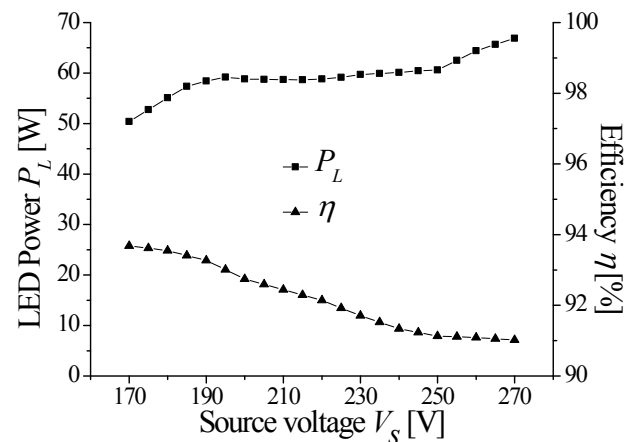

(a)

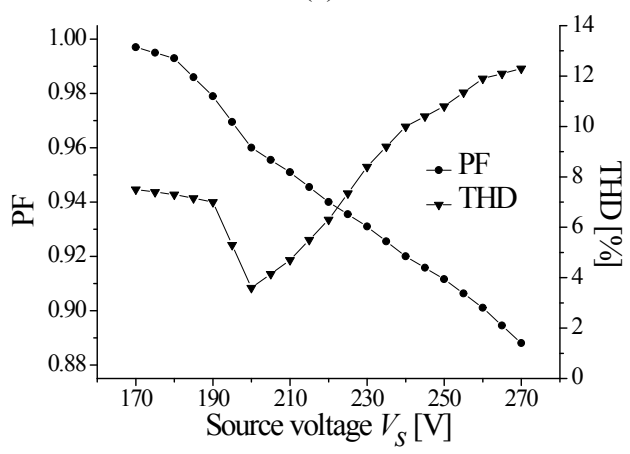

(b)

Fig. 16. Experimental results of the $P_{L}, \eta, \mathrm{PF}$, and THD w.r.t. the $V_{s}$ at $f_{s}=60 \mathrm{~Hz}$. (a) The LED power $P_{L}$ and efficiency $\eta$. (b) The $\mathrm{PF}$ and THD.

modulating the volume resistor $R_{1}$. For instance, $P_{L}$ can be changed from $76 \mathrm{~W}$ to $40 \mathrm{~W}$ at $V_{s}=220 \mathrm{~V}$, where over 2.7 $\mathrm{M} \Omega$ of $R_{1}$ cannot be used for the LED dimming range because $v_{5}$ in Fig. 5 cannot reach $V_{D}$ within the control time $T_{c}$.

As can be seen from Fig. 13, $R_{1}$ was selected to satisfy $P_{L}$ $=60 \mathrm{~W}: R_{1}=0.75 \mathrm{M} \Omega, 1.63 \mathrm{M} \Omega$, and $2.4 \mathrm{M} \Omega$ for $V_{s}=190 \mathrm{~V}$, $220 \mathrm{~V}$, and $250 \mathrm{~V}$, respectively. Based on these values, the experimental waveforms of $v_{s}, v_{o}, v_{4}$, and $v_{5}$ were measured, as shown in Fig. 14, where $T_{c}$ increased as $V_{s}$ increased, as anticipated from Fig. 5.

\section{B. LED Power Regulation}

As shown in Fig. 15, the experimental waveforms of $v_{5}, v_{c}$, $i_{L}$, and $v_{L}$ were measured to verify the LED power regulation by the proposed control circuit. When $V_{s}=190 \mathrm{~V}, V_{c}$ became $-15.0 \mathrm{~V}$, which is the minimum value of $v_{c}$. However, when $V_{s}>190 \mathrm{~V}$, the LED power regulation began, which is identified by $v_{c}>0$. For instance, $v_{c}=8.5 \mathrm{~V}$ for $V_{s}=220 \mathrm{~V}$, and $v_{c}=12.3 \mathrm{~V}$ for $V_{s}=250 \mathrm{~V}$. In this way, $P_{L}$ was found to be well regulated for $190 \mathrm{~V}<V_{s}<250 \mathrm{~V}$ by the proposed control circuit. The time constant of the control circuit was measured as $0.4 \mathrm{~s}$, as shown in Figs. 15(e) and (f), which can be varied, as can be seen from (13c).

The LED power and total efficiency of the proposed LED driver were also measured, as shown in Fig. 16(a), where the maximum LED power variation was well mitigated to within $\pm 2 \%$ and the maximum efficiency was between $93.3 \%$ and $91.1 \%$ for $190 \mathrm{~V}<V_{s}<250 \mathrm{~V}$. This power variation, $\pm 2 \%$, of the proposed LED driver is quite negligible in practice. As shown in Fig. 16(b), the measured results of the PF and THD satisfy the global standards for $190 \mathrm{~V}<V_{s}<250 \mathrm{~V}$ [45]-[46]. Furthermore, all of the harmonics of the source current $i_{s}$ satisfy the IEC61000-3-2 class C standard, as shown in Fig. 17. The measurement results for each $V_{s}$ are summarized in Table III.

\section{CONCLUSION}

The proposed TRIAC dimming LED driver by variable switched capacitance has been verified for $60 \mathrm{~W}$ LED applications. The LED power can be successfully regulated to within $\pm 2 \%$ for a wide range of $190 \mathrm{~V}<V_{s}<250 \mathrm{~V}$. The measured THD, PF, and power efficiency were $6.3 \%, 0.94$, and $92.3 \%$ at $V_{s}=220 \mathrm{~V}$, respectively. The temperature increase of the LED driver was merely $6^{\circ} \mathrm{C}$. With this novel TRIAC dimming LED driver, high efficiency and a long lifespan were achieved, since these are inherent merits of passive-type LED drivers. In addition, LED dimming and LED power regulation were successfully realized. Thus, the proposed LED driver is expected to be utilized in industrial lighting applications such as streets, factories, parking garages, and emergency stairs.

\section{ACKNOWLEDGMENT}

This work was supported by a Korea Micro Energy Grid (K-MEG) of the Korea institute of Energy Technology Evaluation and Planning (KETEP) grant funded by the Korean government Ministry of Trade, Industry and Energy (MOTIE). (No. 2011T100100024).

\section{REFERENCES}

[1] M. R. Krames, O. B. Shchekin, R. Mueller-Mach, G. O.Mueller, L. Zhou, G. Harbers, and M. G. Craford, "Status and future of high-power light-emitting-diodes for solid-state lighting," Journal of Display Technology, Vol. 3, No. 2, pp. 160-175, Jun. 2007. 
[2] J. Cardesin, J. Ribas, J. Garcia-Garcia, M. Rico-Secades, A. J. Calleja, E. L. Corominas, and M. A. Dalla Costa, "LED permanent emergency lighting system based on a single magnetic component," IEEE Trans. Power Electron., Vol. 24, No. 5, pp. 1409-1416, May 2009.

[3] D. A. Steigerwald, J. C. Bhat, D. Collins, R. M. Fletcher,M. O. Holcomb, M. J. Ludowise, P. S. Martin, and S. L. Rudaz, "Illumination with solid state lighting technology," IEEE $J$. Sel. Topics Quantum Electron., Vol. 8, No. 2, pp. 310-320, Apr. 2002.

[4] Matthias Wendt and Jan-Willem Andriesse, "LEDs in real lighting applications: from niche markets to general lighting," IEEE Industry Applications Conference, pp. 2601-2603, 2006

[5] S. Y. (Ron) Hui and Y. X. Qin, "A general photo-electro-thermal theory for light emitting diode (LED) systems," IEEE Trans. Power Electron., Vol. 24, No. 8, pp. 1967-1976, Aug. 2009.

[6] Y. K. Cheng and K. W. E. Cheng, "General study for using LED to replace traditional lighting devices," IEEE International Conference on Power Electronics Systems and Applications (ICPESA), pp. 173-177, 2006.

[7] M. S. Shur and R. Zukauskas, "Solid-state lighting: toward superior illumination," in Proc. the IEEE, Vol. 93, No. 10, pp. 1691-1703, 2005.

[8] K. Streubel, N. Linder, R. Wirth, and A. Jaeger, "High brightness AlGaInP light-emitting diodes," IEEE J. Sel. Topics Quantum Electron., Vol. 8, No. 2, pp. 321-332, Mar. 2002.

[9] Q. Hu and R. Zane, "A 0.9 PF LED driver with small LED current ripple based on series-input digitally-controlled converter modules," IEEE Applied Power Electronics Conference and Exposition (APEC), pp. 2314-2320, 2010.

[10] J. M. Alonso, J. Viña, D. G. Vaquero, G. Martínez, and R. Osorio, "Analysis and design of the integrated double buck-boost converter as a high-power-factor driver for power-LED lamps," IEEE Trans. Ind. Electron., Vol. 59, No. 4, pp. 1689-1697, Apr. 2012.

[11] Q. $\mathrm{Hu}$ and R. Zane, "LED driver circuit with series-input-connected converter cells operating in continuous conduction mode," IEEE Trans. Power Electron., Vol. 25, No. 3, pp. 574-582, Mar. 2010.

[12] Z. Ye, F. Greenfeld, and Z. Liang, "Single-stage offline SEPIC converter with power factor correction to drive high brightness LEDs," IEEE Applied Power Electronics Conference and Exposition (APEC), pp. 546-553, 2009.

[13] Y. Hu, L. Huber, and M. M. Jovanovi', "Single-stage, universal-input AC/DC LED driver with current-controlled variable PFC boost inductor," IEEE Trans. Power Electron., Vol. 27, No. 3, pp. 1579-1588, Mar. 2012.

[14] X. Xie, J. Wang, C. Zhao, Q. Lu, and S. Liu, "A novel output current estimation and regulation circuit for primary side controlled high power factor single-stage flyback LED driver," IEEE Trans. Power Electron., Vol. 27, No. 11, pp. 4602-4612, Nov. 2012.

[15] Y. Zhou, X. Li, X. Ye, and G. Zhai, "A remaining useful life prediction method based on condition monitoring for LED driver," IEEE conference on Prognostics and System Health Management (PHM), pp. 1-5, 2012.

[16] Q. Hu and R. Zane, "Minimizing required energy storage in off-line LED drivers based on series-input converter modules," IEEE Trans. Power Electron., Vol. 26, No. 10, pp. 2887-2895, Oct. 2011.
[17] Y. Hu and M. M. Jovanovic, "A novel LED driver with adaptive drive voltage," IEEE Applied Power Electronics Conference and Exposition (APEC), pp. 565-571, 2008.

[18] M. Ali, M. Orabi, M. E. Ahmed, and A. El-Aroudi, "Design consideration of modified SEPIC converter for LED lamp driver," IEEE Power Electronics for Distributed Generation Systems (PEDG), pp. 394-399, 2010.

[19] D. Gacio, J. M. Alonso, A. J. Calleja, J. Garcia, and M. Rico-Secades, "A universal-input single-stage high-power-factor power supply for HB-LEDs based on integrated buck-flyback converter," IEEE Trans. Ind. Electron., Vol. 58, No. 2, pp. 589-599, Feb. 2011.

[20] J. M. Alonso, J. Viña, D. G. Vaquero, G. Martínez, and R. Osorio, "Analysis and design of the integrated double buck-boost converter as a high-power-factor driver for power-LED lamps," IEEE Trans. Ind. Electron., Vol. 59, No. 4, pp. 1689-1697, Apr. 2012.

[21] S. Y. R. Hui, S. N. Li, X. H. Tao, W. Chen, and W. M. Ng, "A novel passive offline LED driver with long lifetime," IEEE Trans. Power Electron., Vol. 25, No. 10, pp. 2665-2672, Oct. 2012.

[22] W. Chen, "A comparative study on the circuit topologies for offline passive light-emitting diode (LED) drivers with long lifetime \& high efficiency," IEEE Energy Conversion Congress and Exposition (ECCE), pp. 724-730, 2010.

[23] B. H. Lee, H. J. Kim, and C. T. Rim, "Robust passive LED driver compatible with conventional rapid-start ballast," IEEE Trans. Power Electron., Vol. 26, No. 12, pp. 3694-3706, Dec. 2011.

[24] E. S. Lee, B. H. Choi, J. P. Cheon, B. C. Kim, and C. T. Rim, "Temperature-robust LC $^{3}$ LED driver with low THD, high efficiency, and long life," IEEE International Power Electronics Conference (IPEC), pp. 3358-3364, 2014.

[25] Y.-H. Liu, Z.-Z. Yang, and S.-C. Wang, "A novel sequential-color RGB-LED backlight driving system with local dimming control and dynamic bus voltage regulation," IEEE Trans. Consum. Electron., Vol. 56, No. 4, pp. 2445-2452, Nov. 2010.

[26] A. Mirvakili and V. Joyner, "A digitally-controlled, bi-level CMOS LED driver circuit combining PWM dimming and data transmission for visible light networks," IEEE GLOBECOM Workshops (GC Wkshps), pp. 1067-1071, 2010.

[27] W. Feng, F. C. Lee, and P. Mattavelli, "Optimal trajectory control of LLC resonant converters for LED PWM dimming," IEEE Trans. Power Electron., Vol. 29, No. 2, pp. 979-987, Feb. 2014.

[28] D. Gacio, J. M. Alonso, J. Garcia, L. Campa, M. J. Crespo, and M. Rico-Secades, "PWM series dimming for slow-dynamics HPF LED drivers: the high-frequency approach," IEEE Trans. Ind. Electron., Vol. 59, No. 4, pp. 1717-1727, Apr. 2012.

[29] J. Zhang, H. Zeng, and T. Jiang, "A primary-side control scheme for high-power-factor LED driver with TRIAC dimming capability," IEEE Trans. Power Electron., Vol. 27, No. 11, pp. 4619-4629, Nov. 2012.

[30] L. Yan, B. Chen, and J. Zheng, "A new TRIAC dimmable LED driver control method achieves high-PF and quality-of-light," IEEE Applied Power Electronics Conference and Exposition (APEC), pp. 969-974, 2012.

[31] J. T. Hwang, M. S. Jung, D. H. Kim, J. H. Lee, M. H. Jung, and J. H. Shin, "Off-the-line primary side regulation LED lamp driver with single-stage PFC and TRIAC dimming using LED forward voltage and duty variation tracking 
control," IEEE J. Solid-State Circuit, Vol. 47, No. 12, pp. 3081-3094, Dec. 2012.

[32] R. Zhang and H. S.-H. Chung, "A TRIAC-dimmable LED lamp driver with wide dimming range," IEEE Trans. Power Electron., Vol. 29, No. 3, pp. 1434-1446, Mar. 2014.

[33] J.-H. Cheng, A. F. Witulski, and J. L. Vollin, "A small-signal model utilizing amplitude modulation for the class-D converter at fixed frequency," IEEE Trans. Power Electron., Vol. 15, No. 6, pp. 1204-1211, Nov. 2000.

[34] A. Katsuki and Y. Sugimoto, "Design of a distortion-free $\mathrm{PFC} \mathrm{CV} / \mathrm{CC}$ ac power supply having variable capacitance devices," IEEE Telecommunications Energy Conference (INTELEC), pp. 1-6, 2011.

[35] T. T. Nguyen, M. F. Kandlawala, A. H. Rahim, and M. A. Alam, "Dynamic performance of a grid connected wind generation system with fuzzy logic controlled variable capacitance compensation," IEEE Australasian Universities Power Engineering Conference (AUPEC), pp. 1-6, 2008.

[36] M. Uenohara, "Noise consideration of the variable capacitance parametric amplifier," IEEE Proceedings of the IRE, Vol. 48, No. 2, pp. 169-179, 1960

[37] J. Huh, S. W. Lee, W. Y. Lee, G. H. Cho, and C. T. Rim, "Narrow-width inductive power transfer system for online electrical vehicles," IEEE Trans. Power Electron., Vol. 26, No. 12, pp. 3666-3679, Dec. 2011

[38] S. Lee, B. Choi, and C. T. Rim, "Dynamics characterization of the inductive power transfer system for online electric vehicles by Laplace phasor transform," IEEE Trans. Power Electron., Vol. 28, No. 12, pp. 5902-5909, Dec. 2013.

[39] C. T. Rim and G. H. Cho, "Phasor transformation and its application to the DC/AC analyses of frequency/phase controlled series resonant converters (SRC)," IEEE Trans. Power Electron., Vol. 5, No. 2, pp. 201-211, Apr. 1990.

[40] C. T. Rim, D. Y. Hu, and G. H. Cho, "Transformers as equivalent circuits for switches: general proofs and D-Q transformation-based analysis," IEEE Trans. Ind. Appl., Vol. 26, No. 4, pp. 777-785, Jul./Aug. 1990.

[41] C. T. Rim, "Unified general phasor transformation for AC converters," IEEE Trans. Power Electron., Vol. 26, No. 9, pp. 2465-2475, Sep. 2011.

[42] C. B. Park, S. W. Lee, and C. T. Rim, "Static and dynamic analyses of three-phase rectifier with LC input filter by Laplace phasor transformation," IEEE Energy Conversion Congress and Exposition (ECCE), pp. 1570-1577, 2012.

[43] N. O. Sokal, K. K. Sum, and D. C. Hamill, "A capacitor-fed, voltage-step-down, single-phase, non-isolated rectifier," IEEE Applied Power Electronics Conference and Exposition (APEC), pp. 208-215, 1998.

[44] V. M. Rajović and N. S. Jovičić, "The capacitive divider power supply and its design problem," IEEE $19^{\text {th }}$ Telecommunications Forum (TELFOR), pp. 852-855, 2011.

[45] ENERGY STAR Program Requirements For Solid State Lighting Luminaires, Eligibility Criteria - Version 1.1, 2008.

[46] Limits for Harmonic Current Emissions (Equipment Input Current $\leq 16$ A per Phase), IEC 61000-3-2 class C Std., 2009.

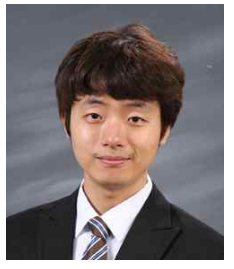

Eun-Soo Lee was born in Korea, in 1986. He received his B.S. degree in Electrical Engineering from Inha University, Incheon, Korea, in 2012, and his M.S. degree in Nuclear and Quantum Engineering from the Korea Advanced Institute of Science and Technology (KAIST), Daejeon, Korea, in 2014. Since 2014, he has been working toward his $\mathrm{Ph} . \mathrm{D}$. degree at KAIST. He has developed LED drivers and wireless power transfer systems. His current research interests include power converters, wireless power transfer systems, and LED drivers.

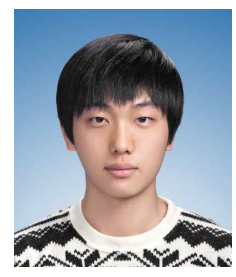

Yeung-Hoon Sohn was born in Korea, in 1990. He received his B.S. and M.S. degrees in Electrical Engineering from the Korea Advanced Institute of Science and Technology (KAIST), Daejeon, Korea, in 2012 and 2014, respectively. Since 2014, he has been working toward his Ph.D. degree at KAIST. He has developed DC-AC converters for plasma discharge and wireless power transfer systems. His current research interests include DC-AC converters for plasma discharge, wireless power transfer systems, and analog circuit design.

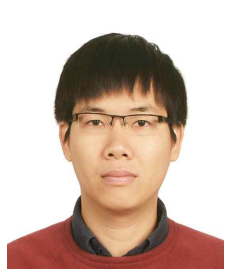

Duy Tan Nguyen was born in Vietnam, in 1987. He received his B.S. degree in Electrical Engineering from the Ho Chi Minh City University of Technology, Ho Chi Minh City, Vietnam, in 2010. Since 2013, he has been working toward his M.S. degree in Nuclear and Quantum Engineering from the Korea Advanced Institute of Science and Technology (KAIST), Daejeon, Korea. From 2010 to 2011, he was an Embedded Automobile Software Engineer at Gate Technology, Ho Chi Minh City, Vietnam. From 2011 to 2013, he was an Embedded Engineer at Koda System, Hanam, Korea, where he conducted research on power measurement instruments. His current research interests include power converters, inverters, wireless power transfer systems, and LED drivers.

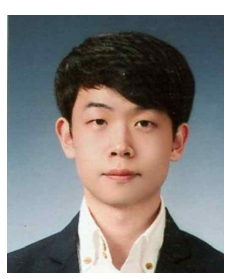

Jun-Pil Cheon was born in Korea, in 1987. $\mathrm{He}$ received his B.S. degree in Electrical Engineering from Kwangwoon University, Seoul, Korea, in 2013, and his M.S. degree in Nuclear and Quantum Engineering from the Korea Advanced Institute of Science and Technology (KAIST), Daejeon, Korea, in 2015. He has developed LED drivers and wireless power transfer systems. His current research interests include power converters, wireless power transfer systems, and LED drivers.

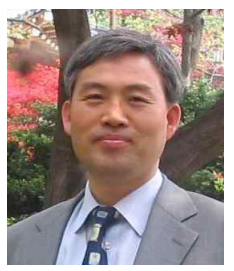

Chun-Taek Rim (M'90-SM'11) was born in Korea, in 1963. He received his B.S. degree in Electrical Engineering from the Kumoh National Institute of Technology (KIT), Gumi, Korea, in 1985, and his M.S. and $\mathrm{Ph} . \mathrm{D}$. degrees in Electrical Engineering from the Korea Advanced Institute of Technology (KAIST), Daejeon, Korea, in 1987 and 1990, respectively. Since 2007, he has been an Associate Professor of Nuclear and Quantum Engineering, and an Adjunct to Aerospace Engineering in Power Electronics at 
KAIST. He is currently developing various wireless power technologies including inductive power transfer systems for on-line electrical vehicles and leading the Nuclear Power Electronics and Robots Lab (PEARL) at KAIST. From 1990 to 1995, he was a Military Officer at the Ministry of National Defense, Korea, and from 1995 to 2003, he was a Senior Researcher at the Agency for Defense Development, Daejeon, Korea. From 1997 to 1999, he was with Astrium Ltd., Portsmouth, U.K. From 2003 to 2007, he was a Senior Director in the Presidential Office, Seoul, Korea. He was involved in developing Korea's first airborne and spaceborne synthetic aperture radars. His current research interests include wireless electric vehicles, wireless power systems for robots and bio-medical applications, and general unified modeling of power electronics. He has authored or coauthored 118 technical papers, written five books, and holds more than 117 patents (awarded and pending). He has won three prizes awarded by the Korean government. He has been the Chair of the Wireless Power Committee of KIPE, since 2010, and the Chair of the EV Charger Committee of KIEE, since 2011. He is now an Associate Editor of IEEE Transactions on Power Electronics and the Journal of Emerging and Selected Topics in Power Electronics (J-ESTPE), a Guest Editor of the Special Issue on Wireless Power Transfer of the IEEE Transactions on Power Electronics and the J-ESTPE. He is also the General Chair of the 2014 IEEE VTC-Workshop on Wireless power (WoW) and the 2015 IEEE WoW. 